\title{
Evaluation of the Neuroprotective Role of Boric Acid in Preventing Traumatic Brain Injury-Mediated Oxidative Stress
}

\author{
Zeki Serdar ATAIZI'*, Mete OZKOC², Gungor KANBAK², Hadi KARIMKHANI ${ }^{3}$, Dilek BURUKOGLU DONMEZ ${ }^{4}$, \\ Novber USTUNISIK², Buket OZTURK ${ }^{5}$ \\ ${ }^{1}$ Eskisehir Yunus Emre State Hospital, Department of Neurosurgery, Eskisehir, Turkey \\ ${ }^{2}$ Eskisehir Osmangazi University, Graduate School of Health Sciences, Department of Medical Biochemistry, Eskisehir, Turkey \\ ${ }^{3}$ Istanbul Medipol University, Graduate School of Health Sciences, Department of Medical Biochemistry, Istanbul, Turkey \\ ${ }^{4}$ Eskisehir Osmangazi University, Graduate School of Health Sciences, Department of Medical Histology and Embryology, Eskisehir, Turkey \\ ${ }^{5}$ Eskisehir Osmangazi University, Faculty of Arts and Sciences, Department of Biology, Eskisehir, Turkey \\ This study has been presented at the $2^{\text {nd }}$ International Brain Research School between 6 and 12 November 2017 at Isparta, Turkey.
}

Corresponding author: Zeki Serdar ATAIZI sataizi@gmail.com

\section{ABSTRACT}

AIM: Oxidative stress (OS) and lipid peroxidation (LP) occur in a cell due to irreversible damage resulting from incidents such as traumatic brain injury (TBI). The aim of our study was to investigate the possible neuroprotective effect of boric acid (BA) by examining the changes in catalase (CAT) activity and levels of CAT and malondialdehyde (MDA) in brain tissues from rats with closed head trauma.

MATERIAL and METHODS: The study consisted of three groups: control ,TBI and TBI + BA. Animals in the control and TBI groups received saline, while animals in the $\mathrm{TBI}+\mathrm{BA}$ group received $\mathrm{BA}$ through daily oral gavage, for 14 days prior to $\mathrm{TBI}$ was performed using the modified Marmarou impact acceleration model. After 24 hours, animals were euthanized and brain tissue obtained to measure the levels of MDA and to assess the activity of CAT.

RESULTS: MDA levels and CAT activity were significantly higher in the TBI group versus the control group. However, they were significantly lower in the TBI + BA group compared to TBI alone. Similarly, edema and necrotic neurons were observed in the TBI group, but not in the control or TBI + BA groups.

CONCLUSION: Based on biochemical and histopathological evidence, we determined that TBI induced LP and OS were inhibited by pre-treatment with BA.

KEYWORDS: Boric acid, Catalase, Malondialdehyde, Oxidative stress, Rat, Traumatic brain injury

\section{INTRODUCTION}

$\mathrm{T}$ Traumatic brain injury (TBI) is among the leading causes of death globally. It is a lethal pathological condition that requires long-term treatment and care. The incidence of head trauma and associated mortality and morbidity continue to rise in today's rapidly accelerating social and technological advancements (1). Initially, the primary brain injury occurs in the central nervous system (CNS) as a result of trauma or physical impact. This leads to scalp injury, skull fracture, contusion, brain laceration, diffuse axonal damage and intracranial bleeding (epidural, subdural, intracerebral). Posttraumatic injury depends on the mechanism of the trauma and the severity of the injury. In more than $20 \%$ of TBI patients, this culminates in death, vegetative state and serious disabilities (12). Following primary insult, neurophysiological and biochemical mediators initiate secondary cell damage (26).
Zeki Serdar ATAIZI (10): 0000-0001-5960-3082 Mete OZKOC

(D) : 0000-0003-3557-4349

Gungor KANBAK

(D) : $0000-0001-7984-3649$
Hadi KARIMKHANI

Dilek BURUKOGLU DONMEZ

Novber USTUNISIK
(1) : 0000-0002-4966-1745
(D) : $0000-0002-6454-4424$

(D) : 0000-0002-0252-2262
Buket OZTURK (1) : 0000-0002-6365-3995 
Thus, pro-inflammatory cytokines cause blood-brain barrier damage, edema, neurodegeneration and apoptosis (38). Furthermore, the formation of reactive oxygen species and lipid peroxidation (LP) leads to release of excitatory glutamate and aspartate, influx of calcium into the cell, and formation of eicosanoids. This disrupts the cell membrane permeability and causes secondary cell damage. Several studies have shown that oxygen free radicals play a key role in the ensuing secondary damage and leads to neurotoxicity $(5,7,23,33)$.

Neurodegeneration due to secondary brain damage negatively affects patient prognosis. Some of these mechanisms can be prevented and the resulting damage can be reduced. Thus, it may be possible to reduce mortality and morbidity. A significant portion of the secondary brain damage is caused by impairment of the balance between antioxidant mechanisms, the levels of reactive oxygen species (ROS), and reactive nitrogen species released in the traumatic brain, and the consequent occurrence of LP. Antioxidants have previously demonstrated a positive effect on the clinical and histopathological outcomes of CNS $(6,11,16,42)$.

Boric acid (BA) and its derivatives are essential trace elements that play a role in metabolic events in plants, animals and humans. Boron is the most common form of BA in the human body. It is soluble in water and has biological sufficiency and effectiveness. It performs its functions without donating protons. Instead, it accepts hydroxyl ions from water and liberates protons.

BA has high affinity for s-adenosyl methionine and oxidized nicotinamide adenine dinucleotide (NAD+). BA forms complexes with hydroxyl group-containing glycolipids, glycoproteins and phosphoinositides. In the complex form it affects membrane integrity, calcium chelation and redox metabolism. When taken consumed, boron rapidly and completely enters the bloodstream. Its urinary excretion rate is approximately $100 \%(17,29,37)$.

BA has been used as an anti-cancer agent and is shown to be effective in reducing the severity and frequency of many inflammatory diseases $(9,19)$. BA also affects calcium, magnesium, potassium, vitamin $\mathrm{D}$, aldehyde dehydrogenase, xanthine oxidase, cytochrome b reductase, insulin, estrogen/ testosterone, T3/T4, triglyceride and glucose metabolism (21).

A study conducted on rats by Ince et al. demonstrated the antioxidant properties of BA and its effectiveness against LP (22). Another study proposed that BA taken at low doses regularly promotes brain development by reducing apoptosis (40).

Our aim in this study was to determine biochemically and histologically whether BA has antioxidant and neuroprotective effects on brain tissue in a rat model of TBI.

\section{MATERIAL and METHODS}

The study protocol was approved by the Institutional Animal Care and Use Committee. National Institutes of Health Guide for Care and Use of Laboratory Animals (445-1/2015) was followed in all the experiments. Twenty-four Wistar albino adult male rats (weighing 260-280 g) were divided into three groups $(n=8)$. Rats were housed in polycarbonate cages in a room with controlled temperature $\left(22 \pm 2{ }^{\circ} \mathrm{C}\right)$ and humidity $(50$ $\pm 5 \%$ ), and a 12-hour light/dark cycle.

\section{Experimental Groups and Drug Administration}

The study sample consisted of three groups ( $n=8$ per group): control, TBI and TBI + BA. The first and second groups received $2 \mathrm{~mL}$ saline and the third was treated with an equal volume of BA at a dose of $100 \mathrm{mg} / \mathrm{kg}$ (dissolved in sterile saline) daily by oral gavage for 14 days prior to TBI.

\section{Head Trauma Model and Collection of Samples}

Twenty-four hours after the last dose of treatments, a modified Marmarou impact acceleration model of TBI was performed in the second and third groups of animals (26). The experimental animals were anesthetized with spontaneous breathing using intramuscular administration of $70 \mathrm{mg} / \mathrm{kg}$ ketamine and $7 \mathrm{mg} /$ kg xylazine hydrochloride.

The rats were placed on the table in the prone position. After their heads were laid on a 10-cm deep foam bed, each rat was subjected to trauma by letting a 450-g cylindrical weight drop freely through a metal tube from a height of $100 \mathrm{~cm}$ toward the coronal and sagittal suture junction area in the cranium.

Following the trauma, all rats were decapitated after 24 hours and the brain tissues were carefully extracted from the trauma boundary into tissue bags for biochemical analysis and frozen $\left(-80^{\circ} \mathrm{C}\right)$ until further examination. In addition, some tissues were fixed in formaldehyde until the histopathological analyses were performed.

\section{Biochemical Examinations}

\section{Measurement of brain tissue malondialdehyde (MDA) levels}

The method used by Ohkawa et al. was used in this study for MDA measurement. The method is based on the color reaction of 1 mole of MDA, (one of the end products of LP) with 2 moles of thiobarbituric acid (31).

Previously frozen tissues were homogenized in $\mathrm{KCl}$ buffer and, the mixtures containing the individual samples were incubated in capped glass tubes for 60 minutes. The resulting pink color compound was photometrically measured at $532 \mathrm{~nm}$ wavelength and the results reported as nmoles/mg protein.

\section{Analysis of brain tissue catalase (CAT) activity}

The CAT activity assay was performed using Beutler's method with $\mathrm{H}_{2} \mathrm{O}_{2}$ as the substrate. Time dependent absorbance was measured at $230 \mathrm{~nm}$ wavelength. Brain tissues homogenized in phosphate buffer were used as samples. The results were calculated according to the number of extinction $(\varepsilon)$ coefficients of $\mathrm{H}_{2} \mathrm{O}_{2}$ at $230 \mathrm{~nm}$ and expressed as $\mathrm{U} / \mathrm{mg}$ protein (2).

\section{Determination of tissue protein levels}

The measurement was performed using Bradford's method. This method is based on a spectrophotometric measurement of blue color at $595 \mathrm{~nm}$ at different intensities of Coomassie 
Brilliant Blue G-250 dye depending on the amount of protein at different concentrations (3).

\section{Histological Examinations}

The brain tissues, from each group were fixed in 10\% formalin for one week. All samples were blocked in paraffin and cut into $5 \mu \mathrm{m}$ thick slices. The deparaffinized tissue sections were then suspended in 96\%, 90\%, 80\%, and $70 \%$ alcohol and distilled water for 5 minutes. Hematoxylin-eosin double staining method was used at this stage. The sections were stained with Hematoxylin for 2 minutes and with Eosin for 10 minutes. The sections were washed with tap water, rapidly passed through the alcohol series and dehydrated. The tissues were made transparent by placing into two separate xyloids for about 30 minutes and the transparent tissues were then mounted with Entellan and evaluated with an Olympus $\mathrm{BH}-2$ light microscope. All preparations containing brain specimens were photographed with an Olympus DP-70 digital camera.

\section{Statistical Analysis}

SPSS 22.0 for Windows was used for statistical analysis. Results were expressed as mean \pm standard deviation. The data were analyzed with Shapiro-Wilk test to determine

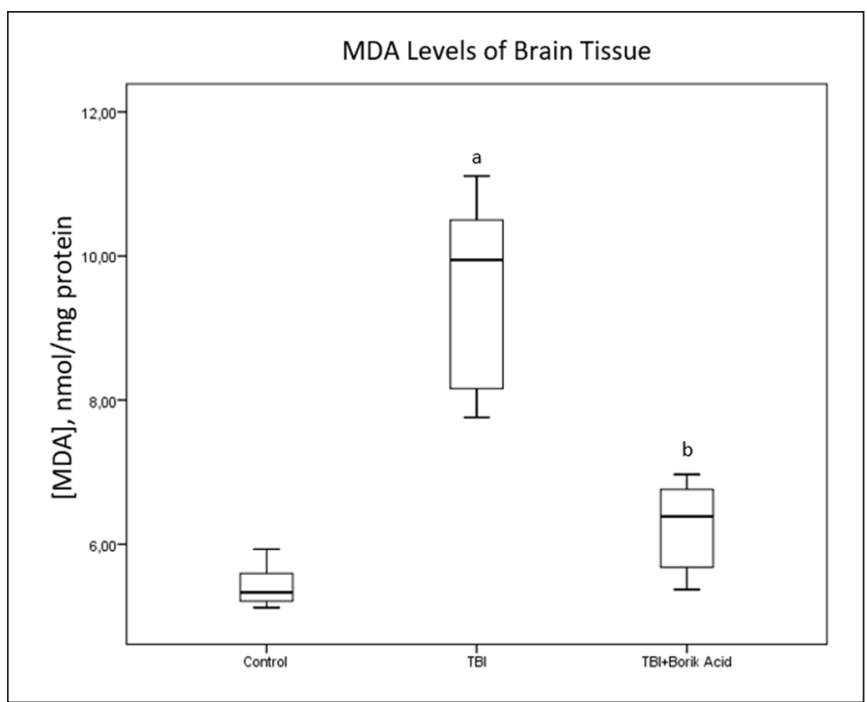

Figure 1: Graph showing MDA levels of brain tissues of the Control, TBI and TBI + Boric Acid groups. a: MDA level of the $T B I$ group is significantly greater than the control group $(p<0.01)$. b: MDA level of TBI + Boric Acid group is significantly lower than the TBI group $(p<0.01)$. whether the distribution of groups was normal. For nonnormal data, the non-parametric Kruskal-Wallis test, was used for statistical analysis and the results were presented as median (minimum-maximum).

\section{RESULTS}

\section{Biochemical Results}

\section{Brain tissue MDA levels}

Figure 1 shows a comparison of all the three groups. The MDA levels of the group with TBI were significantly higher than the control group $(p<0.01)$. In contrast, TBI + BA group showed lower MDA levels compared to TBI alone $(p<0.01)$ (Figure 1 , Table I).

\section{Brain tissue CAT activity}

The data demonstrate that CAT activity of the TBI group was higher than the control group. CAT activity in the TBI group was $3.49 \pm 0.32$ and reduced to $6.43 \pm 0.97$ in the TBI + BA group. This difference was statistically significant $(p<0.01)$ (Figure 2, Table I).

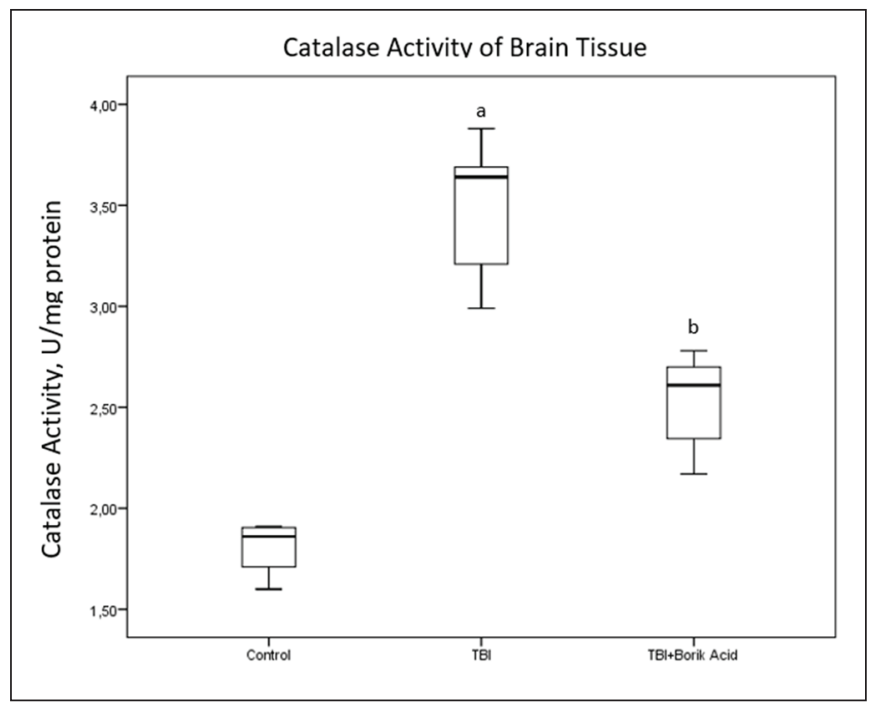

Figure 2: Graph showing catalase (CAT) activity of brain tissues in the Control, TBI and TBI + BA groups. a: CAT activity of TBI group is significantly greater that of the control group $(p<0.01)$. b: CAT activity of TBI + BA group is significantly lower than the CAT activity of TBI group $(p<0.01)$.

Table I: Brain Tissue Malondialdehyde Levels and Catalase Activities of the Experimental Groups and Their Comparisons

\begin{tabular}{lccc}
\hline Group & $\mathbf{n}$ & $\begin{array}{c}\text { Malondialdehyde (nmol/mg protein) } \\
\text { Median (min-max) }\end{array}$ & $\begin{array}{c}\text { Catalase Activity (U/mg protein) } \\
\text { Median (min-max) }\end{array}$ \\
\hline Control & 8 & $5.33(5.12-5.93)$ & $1.86(1.60-1.91)$ \\
\hline TBI & 8 & $9.95(7.76-11.11)^{\mathrm{a}}$ & $3.64(2.99-3.88)^{\mathrm{a}}$ \\
\hline $\mathrm{TBI}+$ Boric Acid & 8 & $6.39(5.37-8.43)^{\mathrm{b}}$ & $2.61(2.17-2.78)^{\mathrm{b}}$ \\
\hline
\end{tabular}

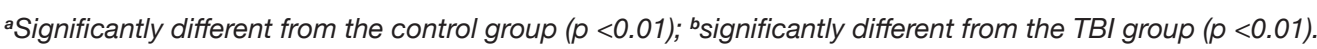




\section{Histological Results}

Histological results show the presence of normal- appearing neurons and glial cells in the control group (Figure 3A, $B)$, whereas edeme and numerous necrotic neurons were observed in the cortical area of the TBI group (Figure 3C, D). Conversely, the cortical area showed less damage, with fewer necrotic neurons and more normal-appearing neurons in the $\mathrm{TBI}+\mathrm{BA}$ group (Figure 3E, F).

\section{DISCUSSION}

Oxidative stress (OS) can be caused by many factors other than head trauma, including cardiac diseases, cancer, and endocrinological and neurological diseases. Head trauma which requires long-term treatment and care, is among the most common causes of death in the world. The incidence of head trauma and associated mortality and morbidity continues to rise due to the rapidly accelerating social and technological advancements of today's world (1).

An imbalance between the production and destruction of endogenous antioxidants, that defend against reactive oxygen products, is called OS. It generally occurs after secondary injury and plays a key role in permanent brain damage (35). In addition, it results in poor patient prognosis. However, some of the underlying mechanisms of secondary damage can be prevented and their negative effects can be reduced. Thus, it may be possible to reduce mortality and morbidity. A significant portion of the secondary brain damage is caused by OS and the oxygen free radicals released due to the disruption of the balance between antioxidant mechanisms in the traumatized brain. Consequently, the oxygen free radicals damage membranes and enzymes, leading to $\operatorname{LP}(4,11,16,42)$.
(A)

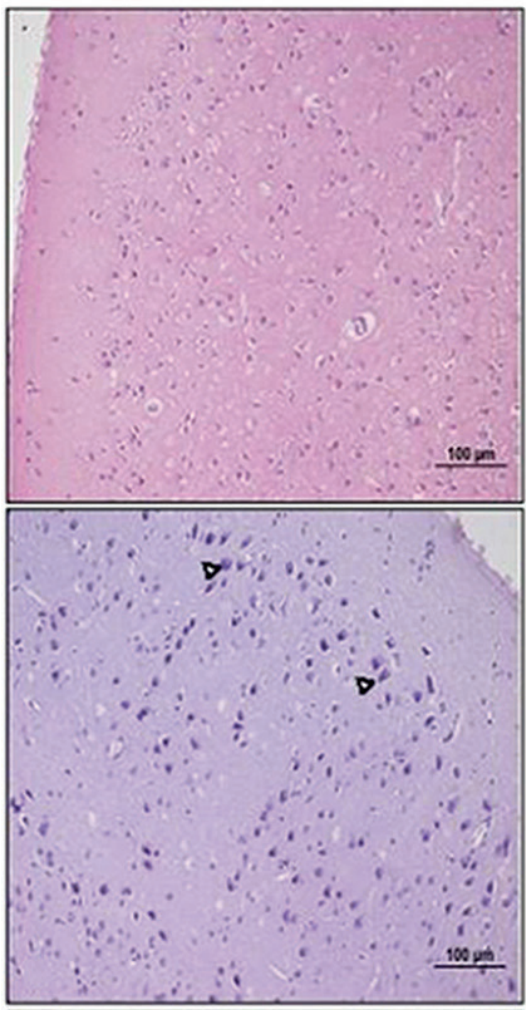

(C)

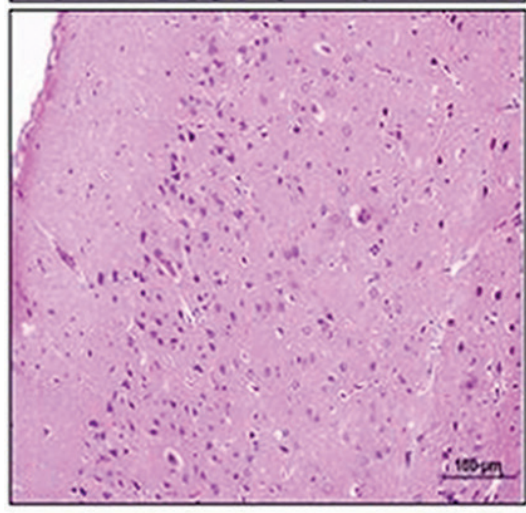

(B)

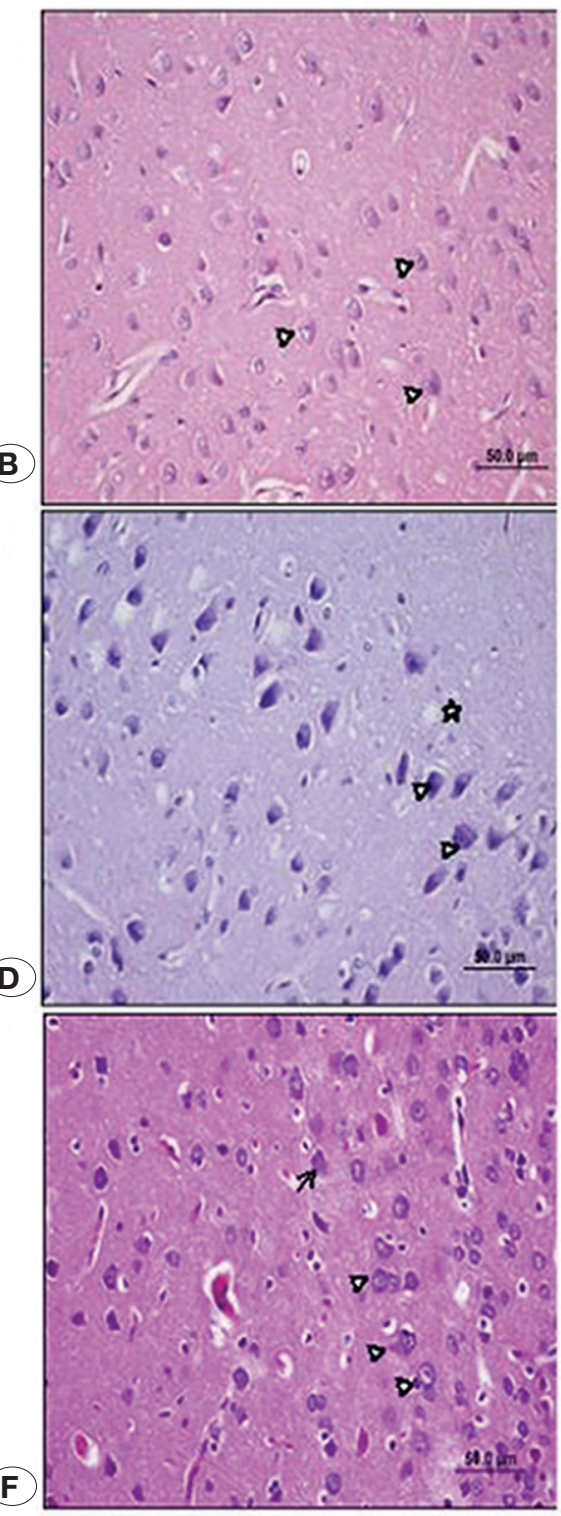

Figure 3: In the control group, normal-looking neurons $(\triangleright)$ and glial cells $(\rightarrow)$ are observed in the cortical area $(\mathbf{A}, \mathbf{B})$. In the traumatic brain injury group, necrotic neurons $(\triangleright)$ and edema $\left(^{*}\right)$ are observed in the cortical area (C, D). In traumatic brain injury + boric acid treated group, fewer necrotic neurons $(\rightarrow)$ and more normal-looking neurons $(\triangleright)$ are evident $(\mathbf{E}, \mathbf{F})$. 
The brain is more susceptible to OS-mediated damage than any other organ (5). Removal of oxidative metabolites formed in the traumatic brain, which has a damaged physiology after trauma, is difficult because of the deterioration of autoregulation. Endogenous antioxidant defense mechanisms constitute enzymes such as CAT, superoxide dismutase (SOD) and glutathione peroxidase (GPx) that protect the cell against OS-induced damage by neutralizing superoxide radicals. CAT is found at low levels, but SOD and GPx are present at moderate levels in cerebral tissue given the brain's vulnerability to oxygen radicals (24). CAT is found in peroxisomes, mitochondria and cytoplasm. CAT catalyzes both catalytic and peroxidative reactions by reacting with hydrogen peroxide. Catalytic activity separates hydrogen peroxide into two molecules: oxygen and water. Although not important at low concentrations, this enzyme is necessary to deal with elevated $\mathrm{H}_{2} \mathrm{O}_{2}$ production (13).

In this study, we investigated CAT activity and levels of MDA, the final product of LP in post-traumatic brain tissue, and the effect of BA on both.

We used the Marmarou trauma model in this study,which is a closed head trauma model produced by weight drop and mimics the pathophysiological changes in the brain (28).

The end product of LP is MDA, which can be used as an indicator of LP $(15,27)$. We observed that MDA level significantly increased in the trauma group in our study. This result is compatible with the relevant literature $(15,27)$.

In 1954, Gershman and Gilbert first reported free oxygen radicals played a key role in primary and secondary damage after head trauma in $(8,24)$. Oxygen free radicals such as superoxide radical, hydrogen peroxide and hydroxyl radical are neurotoxic (20).

Following trauma, the brain may return to normal physiology when it is protected from secondary damage caused by oxidants. Therefore, antioxidant mechanisms of the brain should be supported. SOD, GPx and CAT are endogenous antioxidants that constitute the main defensive line against OS under physiological conditions (10,39). In 1997, Goss et al. assessed GPx and CAT activity in experimental animals versus controls in a rodent model of TBI (14). They found significantly higher levels of CAT in cortical tissue of the injured brains than in the control group animals. We also observed a similar result in our study. Previous research showed that antioxidant enzyme activity is reduced in case of OS (27). Thus, it is necessary to reduce the production or distribution of oxygen free radicals. Agents inhibiting oxygen free radicals were reported to protect against the detrimental effects of trauma or ischemia in the CNS. The effect of these radicals can be determined by measuring CAT and GPx activity $(16,23,42)$.

Oxygen free radical inhibitors were reported to have a beneficial effects on clinical and histopathological outcomes of CNS trauma $(11,16,42)$. Suggesting a pharmacological basis for the treatment of head trauma in 1972, Ortega reported that the destruction in the damaged brain tissue originated, in particular, from oxygen free radicals, and that the main step in this event was the increase in vascular permeability, due to oxygen free radicals. Long et al. suggested that antioxidant substances could be used in the treatment of post-traumatic brain edema $(25,36)$.

Accordingly, progesterone, vitamin E, vitamin C, vitamin D and $\mathrm{N}$-acetylcysteine have been used as antioxidants in clinical trials for TBI with positive results reported (34).

The exact mechanism of the antioxidant and neuroprotective effects of BA remain unclear (32). However, benefits are hypothesized to be a combination of BA's cell membrane function and enzymatic reactions $(18,30)$. Ince et al. found that the antioxidant activity increased and LP decreased when 100 $\mathrm{mg} / \mathrm{kg} / \mathrm{day}$ of boron was administered (22). Weir and Fisher used BA at a dose of $100 \mathrm{mg} / \mathrm{kg} /$ day and determined that it was not toxic to rodents when used for short durations $(\leq 4$ weeks) (41).

Another study showed that low-dose BA had a stabilizer effect by regulating the permeability of the blood brain barrier by protease inhibition in endothelial cells and had neuroprotective effects by regulating vascular permeability during inflammation (9).

In light of these findings, we conducted this study to assess for the first time the neuroprotective effect of BA in a rat model of TBI. We observed a significant difference in both histopathological and tissue measurement results between the BA-untreated trauma group and the BA-treated trauma group. We also observed that the group with TBI had significantly higher levels of MDA than the control group. BA administration significantly reduced the MDA level indicating anti-inflammatory effect by blocking vascular permeability (9).

We also obtained a similar result in the measurement of CAT activity, an antioxidant enzyme. As might be expected, this significant reduction in CAT activity in the trauma group treated with BA compared to saline-treated TBI group may be related to reduction in the CAT enzyme consumption. Histopathologically, we established that the trauma group treated with BA had remarkably lower levels of necrotic cell death and edema compared to the animals with untreated TBI.

\section{- CONCLUSION}

Trauma triggers secondary damage cascades in brain tissue that leads to neuroinflammation, production of ROS, LP and apoptosis. In this study, we observed that TBI-mediated neuronal damage was reduced by pre-treatment with BA. On the other hand, there is a need for future experimental and clinical studies to support the neuroprotective effects of BA.

\section{ACKNOWLEDGEMENTS}

Preparation for publication of this article is partly supported by Turkish Neurosurgical Society. 


\section{- REFERENCES}

1. Baldo V, Marcolongo A, Floreani A, Majori S, Cristofolettil M, Dal Zotto A, Vazzoler G, Trivello R: Epidemiological aspect of traumatic brain injury in Northeast Italy. Eur $\mathrm{J}$ Epidemiol 18:1059-1063, 2003

2. Beutler E: Red cell metabolism a manual of biochemical method, 3th ed. New York: Grune and Stratton, 1973

3. Bradford MM: A rapid and sensitive method for the quantitation of microgram quantities of protein utilizing the principle of protein-dye binding. Anal Biochem 72:248-254, 1976

4. Brocardo PS, Gil-Mohapel J, Christie BR: The role of oxidative stress in fetal alcohol spectrum disorders. Brain Res Rev 67:209-225, 2011

5. Bryan J, Galbraith SL: Head injuries: Pathology and natural history of head injury. In: An Introduction to Neurosurgery, $4^{\text {th }}$. London: William Heinemann, 1983

6. Chen G, Shi J, Hu Z, Hang C: Inhibitory effect on cerebral inflammatory response following traumatic brain injury in rats: A potential neuroprotective mechanism of $\mathrm{N}$-acetylcysteine. Mediators Inflamm 2008:716458, 2008

7. Clasen RA, Pandolfi S, Laing I, Casey DJ: Experimental study of relation of fever to cerebral edema. J Neurosurg 41:576581,1974

8. Cohen G: Oxy-radical toxicity in catecholamine neurons. Neurotoxicology 5:77-82, 1984

9. Colak S, Geyikoglu F, Keles ON, Turkez H, Topal A, Unal B: The neuroprotective role of boric acid on aluminum chlorideinduced neurotoxicity. Toxicol Ind Health 27:700-710, 2011

10. DeKosky ST, Taffe KM, Abrahamson EE, Dixon CE, Kochanek PM, Ikonomovic MD: Time course analysis of hippocampal nerve growth factor and antioxidant enzyme activity following lateral controlled cortical impact brain injury in the rat. $J$ Neurotrauma 21:491-500, 2004

11. Dohi K, Satoh K, Nakamachi T, Yofu S, Hiratsuka K, Nakamura S, Ohtaki H, Yoshikawa T, Shioda S, Aruga T: Does edaravone (MCl-186) act as an antioxidant and a neuroprotector in experimental traumatic brain injury? Antioxid Redox Signal 9:281-287, 2007

12. Finfer SR, Cohen J: Severe traumatic brain injury. Resuscitation 48:77-90, 2001

13. Gandhi S, Abramov AY: Mechanism of oxidative stress in neurodegeneration. Oxid Med Cell Longev 2012:428010, 2012

14. Goss JR, Taffe KM, Kochanek PM, DeKosky ST: The antioxidant enzymes glutathione peroxidase and catalase increase following traumatic brain injury in the rat. Exp Neurol 146:291-294, 1997

15. Hiebert JB, Shen Q, Thimmesch AR, Pierce JD: Traumatic brain injury and mitochondrial dysfunction. Am J Med Sci 350:132-138, 2015

16. Huh PW, Belayev L, Zhao W, Clemens JA, Panetta JA, Busto R, Ginsberg MD: Neuroprotection by LY341122, a novel inhibitor of lipid peroxidation, against focal ischemic brain damage in rats. Eur J Pharmacol 389:79-88, 2000

17. Hunt CD: Boron. In: Coates PM, Blackman MR, Cragg GM, Levine M, Moss J and White JD (eds). Encyclopedia of Dietary Supplements. $1^{\text {st }}$ ed. New York: Marcel Dekker, 2005:55-65
18. Hunt CD: The biochemical effects of physiologic amounts of dietary boron in animal nutrition models. Environ Health Perspect 102:35-43, 1994

19. Hunt CD, Idso JP: Dietary boron as a physiological regulator of the normal inflammatory response: A review and current research progress. J Trace Elem Exp Med 12:221-233, 1999

20. Ikeda Y, Long DM: The molecular basis of brain injury and brain edema: The role of oxygen free radicals. Neurosurgery 27:1-11, 1990

21. Ince S, Keles H, Erdogan M, Hazman O, Kucukkurt I: Protective effect of boric acid against carbon tetrachloride-induced hepatotoxicity in mice. Drug Chem Toxicol 35:285-292, 2012

22. Ince S, Kucukkurt I, Cigerci IH, Fatih Fidan A, Eryavuz A: The effects of dietary boric acid and borax supplementation on lipid peroxidation, antioxidant activity, and DNA damage in rats. J Trace Elem Med Biol 24:161-164, 2010

23. Inci S, Ozcan OE, Kilinc K: Time-level relationship for lipid peroxidation and the protective effect of alpha-tocopherol in experimental mild and severe brain injury. Neurosurgery 43:330-336, 1998

24. Kontos HA, Wei EP: Superoxide production in experimental brain injury. J Neurosurg 64:803-807, 1986

25. Long DM, Maxwell ER, Choi KS, Cole HO, French LA: Multiple therapeutic approaches in the treatment of brain edema induced by a standard cold lesion. In: Steroids and Brain Edema. Newyork:Springer Verlag, 1972:87-94

26. Lorente L: New Prognostic biomarkers in patients with traumatic brain injury. Arch Trauma Res 4:e30165, 2015

27. Lozano D, Gonzales-Portillo GS, Acosta S, de la Pena I, Tajiri $\mathrm{N}$, Kaneko Y, Borlongan CV: Neuroinflammatory responses to traumatic brain injury: Etiology, clinical consequences, and therapeutic opportunities. Neuropsychiatr Dis Treat 11:97106, 2015

28. Marmarou A, Foda MA, van den Brink W, Campbell J, Kita $H$, Demetriadou K: A new model of diffuse brain injury in rats. Part I: Pathophysiology and biomechanics. J Neurosurg 80:291-300, 1994

29. Nielsen FH: Is boron nutritionally relevant? Nutr Rev 66:183191, 2008

30. Nielsen FH: Nutritional requirements for boron, silicon, vanadium, nickel, and arsenic: Current knowledge and speculation. FASEB J 5:2661-2667, 1991

31. Ohkawa H, Ohishi N, Yagi K: Assay for lipid peroxides in animal tissues by thiobarbituric acid reaction. Anal Biochem 95:351-358, 1979

32. Pawa S, Ali S: Boron ameliorates fulminant hepatic failure by counteracting the changes associated with the oxidative stress. Chem Biol Interact 160:89-98, 2006

33. Petty MA, Poulet P, Haas A, Namer IJ, Wagner J: Reduction of traumatic brain injury-induced cerebral oedema by a free radical scavenger. Eur J Pharmacol 307:149-155, 1996

34. Rodriguez-Rodriguez A, Egea-Guerrero JJ, Murillo-Cabezas F, Carrillo-Vico A: Oxidative stress in traumatic brain injury. Curr Med Chem 21:1201-1211, 2014

35. Sies H: Oxidative stress: From basic research to clinical application. Am J Med 91:31S-38S, 1991 
36. Sies $H$, Stahl W, Sundquist AR: Antioxidant functions of vitamins. Vitamins $\mathrm{E}$ and $\mathrm{C}$, beta-carotene, and other carotenoids. Ann N Y Acad Sci 669:7-20, 1992

37. Sogut I, Oglakci A, Kartkaya K, OI KK, Sogut MS, Kanbak G, Inal ME: Effect of boric acid on oxidative stress in rats with fetal alcohol syndrome. Exp Ther Med 9:1023-1027, 2015

38. Stahel PF, Morganti-Kossmann MC, Perez D, Redaelli C, Gloor $\mathrm{B}$, Trentz O, Kossmann T: Intrathecal levels of complementderived soluble membrane attack complex (sC5b-9) correlate with blood-brain barrier dysfunction in patients with traumatic brain injury. J Neurotrauma 18:773-781, 2001
39. Sun Y, Oberley LW, Li Y: A simple method for clinical assay of superoxide dismutase. Clin Chem 34:497-500, 1988

40. Tang J, Zheng X, Xiao K, Wang K, Wang J, Wang Y, Wang K, Wang W, Lu S, Yang K, Sun PP, Khaliq H, Zhong J, Peng $\mathrm{KM}$ : Effect of boric acid supplementation on the expression of BDNF in African Ostrich chick brain. Biol Trace Elem Res 170:208-215, 2016

41. Weir RJJ, Fisher RS: Toxicologic studies on borax and boric acid. Toxicol Appl Pharmacol 23:351-364, 1972

42. Wilson JX, Gelb AW: Free radicals, antioxidants, and neurologic injury: Possible relationship to cerebral protection by anesthetics. J Neurosurg Anesthesiol 14:66-79, 2002 